\title{
Comparative study of partial discharge emulators for the calibration of free-space radiometric measurements.
}

\author{
JABER, A., LAZARIDIS, P., SAEED, B., ZHANG, Y., KHAN, U., UPTON, D., \\ AHMED, H., MATHER, P., VIEIRA, M.F.Q., ATKINSON, R., JUDD, M. and \\ GLOVER, I.A.
}

(C) 2016 IEEE. Personal use of this material is permitted. Permission from IEEE must be obtained for all other uses, in any current or future media, including reprinting/republishing this material for advertising or promotional purposes, creating new collective works, for resale or redistribution to servers or lists, or reuse of any copyrighted component of this work in other works.

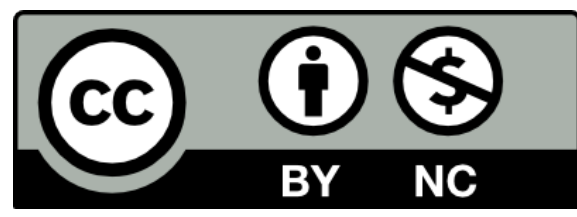




\title{
Comparative study of Partial Discharge Emulators for the Calibration of Free-Space Radiometric Measurements
}

\author{
A Jaber ${ }^{1}$, P Lazaridis ${ }^{1}$, B Saeed ${ }^{1}$, Y Zhang ${ }^{1}$, U Khan ${ }^{1}$, D Upton ${ }^{1}$, H Ahmed ${ }^{1}$, \\ P Mather $^{1}$, M F Q Vieira ${ }^{2}$, R Atkinson ${ }^{3}, \mathrm{M} \mathrm{Judd}^{4}$, and I A Glover ${ }^{1}$ \\ ${ }^{1}$ Department of Engineering \& Technology, University of Huddersfield, Huddersfield HD1 3DH, UK \\ ${ }^{2}$ Department of Electrical Engineering, Universidade Federal de Campina Grande, Campina Grande, Brazil \\ ${ }^{3}$ Deptartment of Electronic and Electrical Engineering, University of Strathclyde, Glasgow G1 1XW, UK \\ ${ }^{4}$ High Frequency Diagnostics \& Engineering Ltd, Glasgow G2 6HJ, UK \\ E-mail: Adel.Jaber@hud.ac.uk
}

\begin{abstract}
Partial discharge is measured simultaneously using free-space radiometry (FSR) and a galvanic contact measurement technique based on the IEC 60270 standard. Several types of PD (Partial Discharge) sources are specially constructed: two internal PD emulators and an emulator of the floating-electrode type. The excitation applied to the source is AC and the radiated signal is captured using a wideband biconical antenna. The calibration of PD sources is demonstrated. Effective radiated power of the $P D$ source using a $P D$ calibration device is determined.
\end{abstract}

Keywords- High voltage; Free space radiometric measurement; galvanic contact measurement; partial discharge; PD calibration.

\section{INTRODUCTION}

The most general technique to estimate the ageing conditions of electrical equipment and power lines is the measurement of PD. PD monitoring is important in the evaluation of the ageing of circuit breakers, power transformers, isolators and switches, cables, GIS, and overhead lines. PD might exist even when the time to failure is still far, thus it is essential to monitor its activity continuously and to detect changes in the peaks of the charge released. PD has traditionally been detected by contact measurement methods (especially IEC 60270) and capacitive/inductive coupling methods. The free-space radiometric (FSR) detection of PD is a relatively new technique.

A galvanic contact measurement uses a frequency band up to several MHz. The apparent charge is typically measured in picocoulombs or nanocoulombs which is the integrated first half cycle of the current pulse, flowing through the PD measurement circuit that is caused by a PD event. Consequently, this technique is well adapted to laboratory measurements, but it is not suitable for on-site monitoring or measuring. For that purpose, a free-space radiometry measurement technique is more advantageous. The VHF and UHF measurement technique is using a frequency band of approximately $50 \mathrm{MHz}$ to $800 \mathrm{MHz}$. The contribution that will be reported in this paper will address the calibration of three types of PD emulator sources utilized for the development and testing of a PD wireless sensor network (WSN). The calibration of the sources suggests the possibility of using free space radiometric measurements to estimate the absolute intensity of $\mathrm{PD}$ in $\mathrm{HV}$ insulation integrity monitoring applications.

\section{PD MEASURING CIRCUIT}

In order to measure PD from different emulator sources, the measuring circuit and the setup for FSR and a galvanic contact measurement are shown in Figure 1.

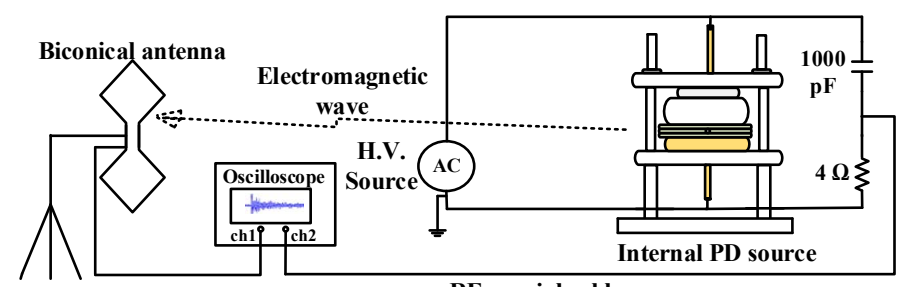

Figure 1. PD measurement circuit with internal PD source.

PD is created by applying AC high voltage (HV) to three types of artificial PD emulators which were measured in the laboratory. Experimental arrangements for producing a PD discharge between floating electrodes, acrylic tube internal discharge (PD discharge in the air and in the oil) and an internal PD discharge are used. The radiometric measurements were made using a biconical antenna connected to a $4 \mathrm{GHz}$ bandwidth, $20 \mathrm{GSa} / \mathrm{s}$, digital sampling oscilloscope (DSO). 
The biconical antenna was located at different distances from the PD source, and was vertically polarised. For detecting PD, a coupling capacitor was connected in parallel with the PD emulator. The voltage rating of the coupling capacitor is 40 $\mathrm{kV}$ in the galvanic contact measurement technique.

\section{PD SOURCE CALIBRATION AND MEASUREMENT}

A commercial PD calibration device that injects a known current pulse of pre-determined intensity is used in our experiments. It is designed to provide consistent charge from 1 $\mathrm{pC}$ to $100 \mathrm{nC}$ and its pulse repetition frequency is $100 \mathrm{~Hz}, 120$ $\mathrm{Hz}$ and $400 \mathrm{~Hz}$. It is suitable for PD tests according to the IEC 60270 standard. With a wide range of calibration pulses, the HVPD calibrator can be used to test all types of $\mathrm{HV}$ equipment in power substations and calculating the PD magnitude of the apparent charge. Figure 2 shows a picture of the HVPD pC calibrator [2].

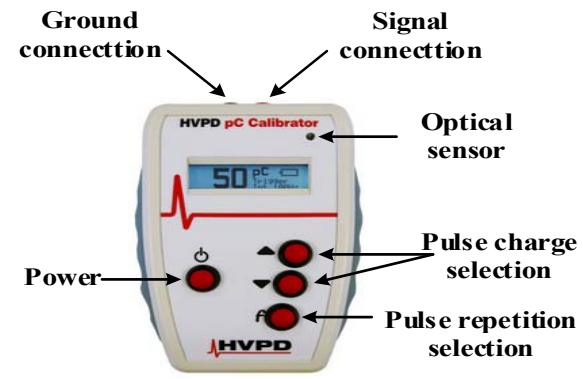

Figure 2. HVPD pC calibrator [2].

Figure 3 shows the waveform of a HVPD pC calibrator pulse injected into a digital sampling oscilloscope (DSO). The input impedance of the channel oscilloscope is $50 \Omega$. Calculated charge by integrating the first half-cycle of the PD source time-series current (measured charge) against the known charge injected by the calibrator (inject charge) is shown in Figure 4. The experimental setup measuring circuit in Figure 5 was used for the calibration PD sources using the commercial $\mathrm{pC}$ calibrator. The output waveform from the calibration measuring circuit is shown in Figure 6. The charge calculated from the galvanic contact measurement appears to be in close agreement with the $\mathrm{pC}$ calibrator.

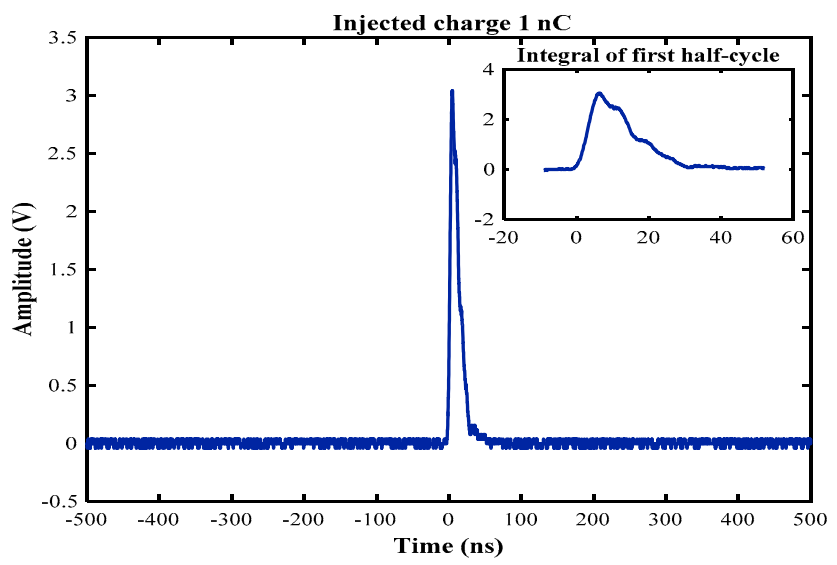

Figure 3. Current waveform for an injected charge of $1 \mathrm{nC}$ into a digital sampling oscilloscope.

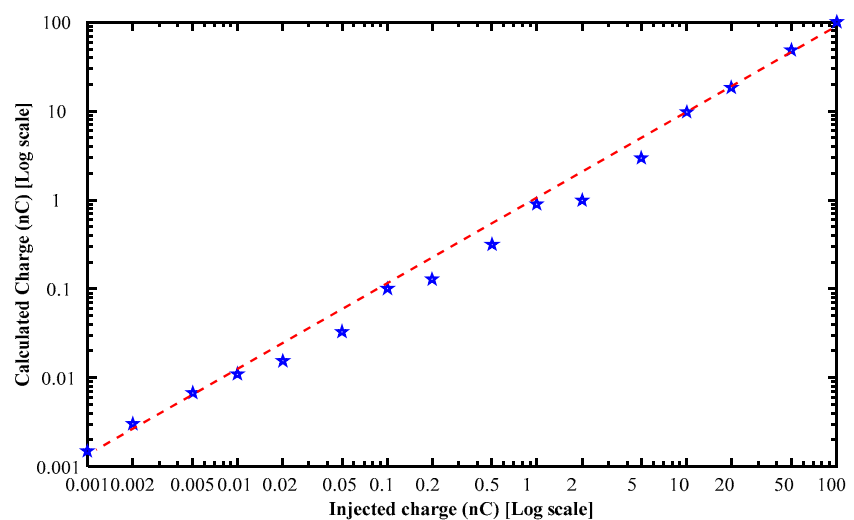

Figure 4. Determined charge by integrating the first half-cycle of pulses versus known injected charge.

Regarding the Free-Space radiometric measurements, four distances were used the measurement system showed in Figure 1 between the three PD emulator sources and the biconical antenna. Table I shows the received mean peak voltage amplitude, the calculated charge and effective radiated power (ERP) for the FSR measurements. The radiated signal amplitude is decreasing by increasing the distance between the PD source and the biconical antenna, due to radiation losses. Received peak voltage, calculated electric field strength and effective radiated power values are presented. The effective radiated power (ERP) of the PD source emulator is estimated from received electric field strength according to the for free space propagation formula (1) as follows:

$$
E(d B \mu V / m)=107+E R P(d B m)-20 \log _{10} d(m)
$$

where $E$ is the electric field strength, ERP is the effective radiated power and $d$ is the $\mathrm{PD}$ source distance from the receiving antenna.

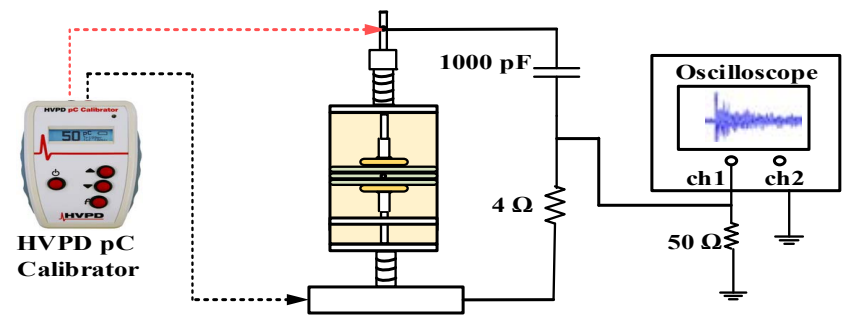

Figure 5. Experimental calibration circuit with acrylic tube PD emulator source.

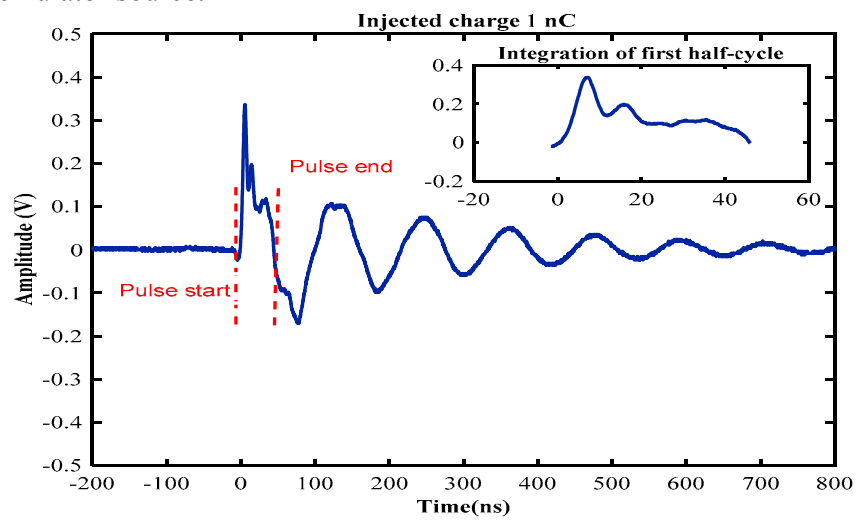

Figure 6. Current waveform for an injected charge of $1 \mathrm{nC}$. 
TABLE I

CONCURRENT MEASUREMENTS OF FSR AND GALVANIC MEASUREMENTS.

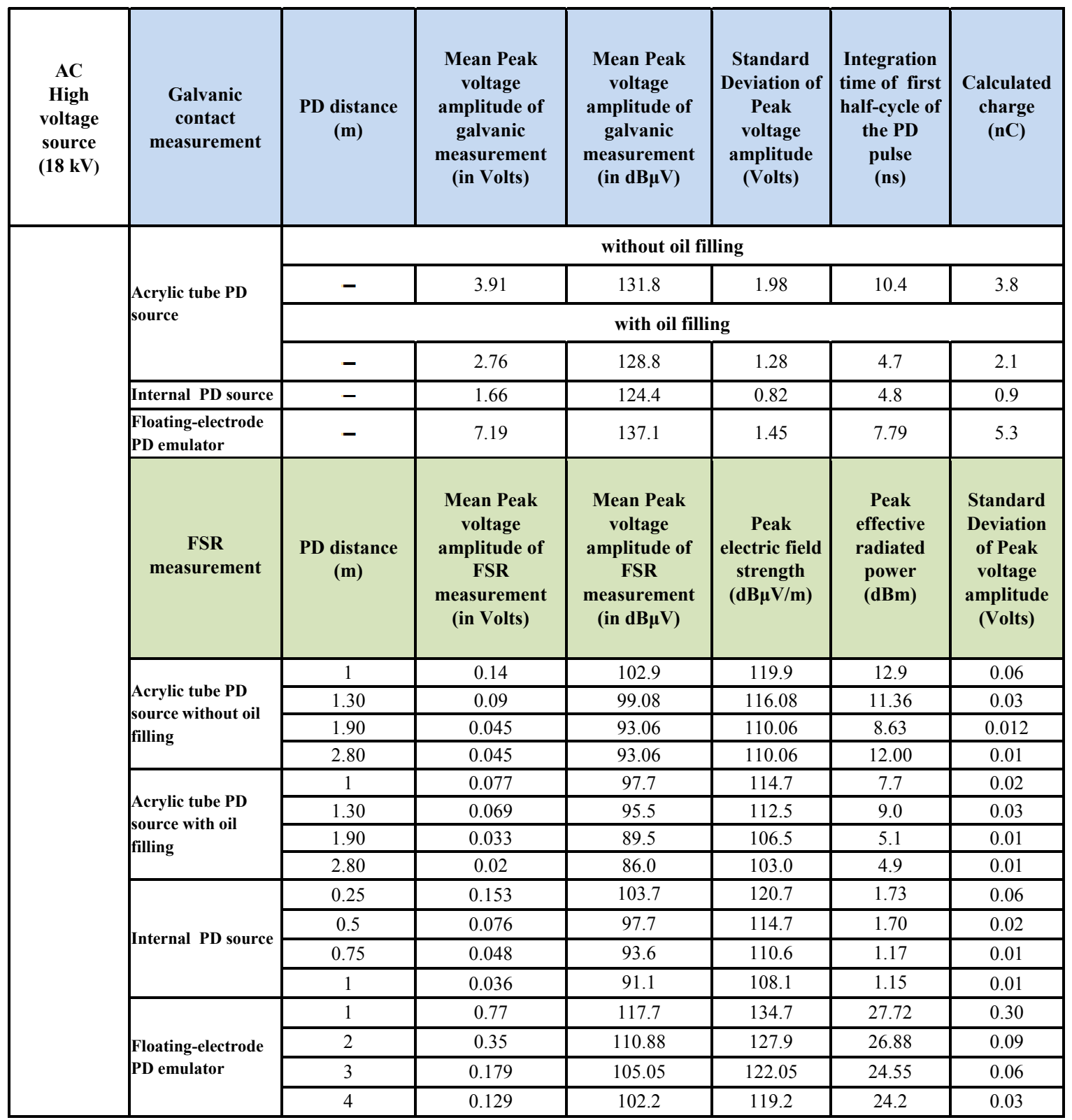

TABLE II

The relationship between calculated charge and effective radiated power (ERP) for different PD emulator source types is presented in Table II. Moreover, Figure 7 shows the effective radiated power for various PD emulator sources as a function of the calculated charge. The acrylic tube internal PD emulator without oil filling and floating PD emulators present a much higher effective radiated power than other types of $\mathrm{PD}$ emulators, in this case by approximately $20-25 \mathrm{~dB}$.
RELATIONSHIP BETWEEN CALCULATED CHARGE AND EFFECTIVE RADIATED POWER OF PD SOURCES

\begin{tabular}{|c|c|c|c|c|}
\hline & $\begin{array}{c}\text { PD } \\
\text { floating- } \\
\text { electrode } \\
\text { PD } \\
\text { source }\end{array}$ & $\begin{array}{c}\text { Acrylic tube } \\
\text { Internal PD } \\
\text { source without } \\
\text { oil filling }\end{array}$ & $\begin{array}{c}\text { Acrylic tube } \\
\text { Internal PD } \\
\text { source with } \\
\text { oil filling }\end{array}$ & $\begin{array}{c}\text { Internal } \\
\text { PD } \\
\text { emulator }\end{array}$ \\
\hline $\begin{array}{c}\text { Calculated } \\
\text { charge } \\
\text { (nC) }\end{array}$ & 5.3 & 3.8 & 2.1 & 0.9 \\
\hline $\begin{array}{c}\text { Average } \\
\text { peak ERP } \\
\text { (dBm) }\end{array}$ & 25.6 & 26.6 & 6.7 & 1.9 \\
\hline
\end{tabular}




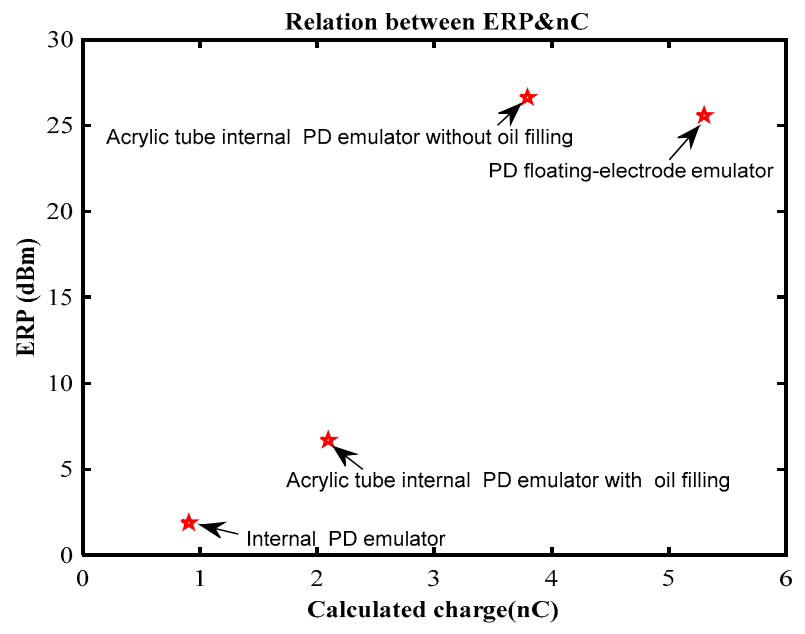

Figure 7. Determined effective radiated power of different types of PD sources versus calculated charge.

\section{CONCLUSIONS}

Partial discharge signals were captured using FSR and galvanic contact measurement techniques. A calibration pulse from a commercial calibrator emulates a PD event of a known intensity. The estimated charge is calculated by integrating the first half-cycle of the PD source time-series current. Estimated charge, peak received voltage, radiated electric field amplitude, and effective radiated power of FSR measurements against the location of the PD emulator are compared for the calibration of FSR signals. Effective radiated power is determined and related to the estimated charge of three different PD emulator sources.

\section{ACKNOWLEDGMENT}

The authors acknowledge the Engineering and Physical Sciences Research Council for their support of this work under grant EP/J015873/1.

\section{REFERENCES}

[1] Meijer, Sander, Martin D. Judd, and Stefan Tenbohlen. "Sensitivity check for radio frequency partial discharge detection for power transformers." Condition Monitoring and Diagnosis. International Conference on. IEEE, Beijing, 21-24 Apr. 2008.

[2] HVPD. Available: http://www.hvpd.co.uk/ (accessed on November 2015).

[3] de Souza Neto, J. M. R., E. C. T. de Macedo, J. S. da Rocha Neto, E. G. Da Costa, S. A. Bhatti, and I. A. Glover. "Partial Discharge Location using Unsynchronized Radiometer Network for Condition Monitoring in HV Substations-A Proposed Approach." In Journal of Physics: Conference Series, vol. 364, no. 1, IOP Publishing, 2012.

[4] Niasar MG, Taylor N, Janus P, Wang X, Edin H, Kiiza R. 'Partial discharges in a cavity embedded in oil-impregnated paper: effect of electrical and thermal aging',. Dielectrics and Electrical Insulation, IEEE Transactions on., 22(2), pp.1071-9, Apr. 2015.

[5] B. Hampton, "UHF diagnostics for gas insulated substations," in High Voltage Engineering. Eleventh International Symposium on (Conf. Publ. No. 467), pp. 6-16, 1999.

[6] A. Jaber, P. Lazaridis, Y Zhang, D Upton, H Ahmed, U Khan, B Saeed, P Mather, M F Q Vieira, R Atkinson, M Judd, and I A Glover, "Comparison of contact measurement and free-space radiation measurement of partial discharge signals," in Automation and Computing (ICAC), 2015, 21st International Conference on 2015. 